\title{
Caracterização física em duas bacias hidrográficas do Alto Juruá, Acre
}

\author{
Eth R. da Silva ${ }^{1}$, Rafael C. Delgado 2 , Leonardo P. de Souza ${ }^{3} \&$ Ismael S. da Silva ${ }^{4}$ \\ ${ }^{1}$ Engenheira Florestal. Cruzeiro do Sul, AC. E-mail: ethsilva@bol.com.br \\ ${ }^{2}$ UFRRJ. Seropédica, RJ. E-mail: rafaelcolldelgado32@gmail.com \\ ${ }^{3}$ UFAC. Cruzeiro do Sul, AC. E-mail: leonardo.acre@gmail.com (Autor correspondente) \\ ${ }^{4}$ Engenheiro Florestal. Cruzeiro do Sul, AC. E-mail: ismael_czs@hotmail.com
}

Palavras-chave:

classificação de imagens digitais morfometria

vetorização de mapas

\section{R E S U M O}

Objetivou-se, neste trabalho, realizar a caracterização física das Bacias Hidrográficas do Igarapé Canela Fina e Igarapé Preto, ambas localizadas no município de Cruzeiro do Sul, AC. Para a classificação não supervisionada empregou-se o ISODATA através dos produtos do sensor TM, a bordo do satélite Landsat-5 fornecidos pelo Instituto Nacional de Pesquisas Espaciais. O período avaliado se estende entre os anos de 2005 a 2010. Os resultados mostram um aumento médio de 48,11\% em áreas desflorestadas para essas bacias e redução média em áreas florestadas de 50,58\%, em consequência de intervenções antrópicas ocorridas ao longo dos últimos anos. As características físicas calculadas demonstraram similaridade entre as bacias hidrográficas, ambas respondem lentamente a eventos hidrológicos e, portanto, não propícias a enchentes. As modificações realizadas ao longo dos últimos anos na superfície das bacias hidrográficas alteraram possivelmente a dinâmica hídrica dos igarapés e os resultados obtidos indicam a eficiência do Sensoriamento Remoto e Sistema de Informação Geográfica na análise da dinâmica espaço-tempo da vegetação e caracterização morfométrica das bacias hidrográficas.

\section{Key words:}

digital image classification morphometric

map vectorisation

\section{Physical characterization of two hydrographical basins in Alto Juruá, Acre}

\begin{abstract}
A B S T R A C T
The aim of this study was to report physical characterization of the hydrographical basins of Igarapé Canela Fina and Igarapé Preto, both located in the municipality of Cruzeiro do Sul, Acre, Brazil. The ISODATA algorithm was used for the non-supervised classification, drawing on data provided by the TM Landsat 5 sensor from the National Institute for Space Research. The covered period of analysis was from 2005 to 2010 . The analysis shows an average increase of $48.11 \%$ of deforested areas and a mean reduction of $50.58 \%$ in the forested areas for both basins, due to anthropic interventions over those five years. The analysis of physical characteristics shows similarities between the hydrographical basins, with both responding slowly to hydrological events, and thus providing conditions not favourable to flooding. Modifications conducted on the surface of the hydrographical basins along the last few years have, however, possibly altered the hydro dynamics of the rivers and streams. The preliminary results indicate that the Remote Sensing and Geographic Information Systems are efficient tools for the analysis of the space-time dynamics of vegetation and the morphometric characterization of hydrographical basins.
\end{abstract}

\section{INTRODUÇÃO}

$\mathrm{O}$ uso adequado dos recursos naturais, principalmente o uso eficiente da água, vem sendo considerado de grande importância de vez que a água está presente em toda a biosfera: nos corpos d'água, no ar, no solo, no subsolo e nos seres vivos desempenhando importantíssima função em quase todas as atividades humanas, econômicas, sociais, culturais e até religiosas (Feldmann, 1992).

A análise desses aspectos do ecossistema envolve características de clima, geomorfologia, solo, vegetação, deflúvio e evapotranspiração, com o que se pode quantificar os processos hidrológicos da bacia e correlacioná-los com as diferentes variáveis, quantidade e qualidade da água, assim como sua dinâmica (Cardoso et al., 2006).
Silveira (2001) define a bacia hidrográfica como área de captação natural da água da precipitação, composta basicamente por um conjunto de superfícies vertentes e de uma rede de drenagem formada por cursos de água que confluem para uma única saída.

A remoção ou alteração da vegetação florestal em determinado ambiente pode influenciar os processos erosivos e até mesmo propagar-se para ambientes adjacentes. A declividade e a cobertura vegetal são fatores significativos que auxiliam a tomada de decisão e o manejo da bacia hidrográfica considerando que essas alterações influenciam a precipitação efetiva, o escoamento superficial e o fluxo da água no solo, dentre outros (Cardoso et al., 2006). 
A geotecnologia é uma ferramenta influente para obtenção dessas variáveis ambientais visto que possibilita a abrangência de análises de grandes áreas, a periodicidade das informações, a vantagem de se monitorar áreas remotas e, consequentemente, de difícil acesso, e a espacialização das informações, como exemplo de aplicação, o mapeamento da cobertura vegetal baseado em imagens de índices (Bezerra et al., 2011).

Algumas faixas espectrais do sensor TM são usadas para caracterização dos índices de vegetação o que reduz o volume de dados a ser analisado ressaltando-se que, praticamente, toda a informação relativa à vegetação, fica resumida a apenas um valor numérico. Este processo facilita, assim, o monitoramento e o estudo do crescimento e desenvolvimento da vegetação (Freitas et al., 2012).

Metodologias baseadas em geotecnologias têm sido desenvolvidas para a classificação automatizada do uso da terra. Os procedimentos atualmente em uso se baseiam na simples investigação da característica radiométrica do pixel (análise multiespectral) sem considerar a provável transformação dessas características no tempo (análise multitemporal) e no espaço (textura) (Delgado et al., 2012b).

$\mathrm{O}$ crescente desenvolvimento do município de Cruzeiro do Sul/AC ocorrido nos últimos anos e modificações ambientais nas bacias hidrográficas do Igarapé Preto e do Canela Fina estão sendo observados por moradores e usuários das bacias hidrográficas; como exemplos são citados a redução da cobertura florestal e o fluxo de água nos igarapés dessas bacias hidrográficas.

Neste sentido propôs-se, com este estudo, realizar a caracterização temporal física da Bacia Hidrográfica do Igarapé Preto (BHIP) e da Bacia Hidrográfica do Igarapé Canela Fina (BHICF) localizadas no município de Cruzeiro do Sul, Acre, utilizando-se o classificador ISODATA e Modelo Digital de Elevação (MDE) respectivamente.

\section{Material e Métodos}

A área de estudo corresponde às bacias hidrográficas que drenam as águas do Igarapé Preto e do Igarapé Canela Fina, localizadas no perímetro rural do município de Cruzeiro do Sul, zona UTM 18S, estado do Acre (Figura 1). O município é caracterizado climaticamente pelas altas temperaturas e elevados índices pluviométricos.

Os dados de imageamento orbital utilizados para determinar as áreas de floresta, desflorestamento e água compreendem imagens do sensor TM a bordo do satélite Landsat-5 (Tabela 1). O ano de 2009 não foi considerado no estudo devido à presença de nebulosidade na cena de estudo.

Tabela 1. Datas de aquisição das cenas Landsat-5 selecionadas e utilizadas para realização do presente estudo, no município de Cruzeiro do Sul, Acre

\begin{tabular}{cccc}
\hline Ano & Sensor & Data & Órbita/Ponto \\
2005 & TM & $14 / 07 / 2005$ & $005 / 65$ \\
& & $14 / 07 / 2005$ & $005 / 65$ \\
2006 & TM & $02 / 08 / 2006$ & $005 / 66$ \\
& & $14 / 05 / 2006$ & $005 / 65$ \\
2007 & TM & $21 / 08 / 2007$ & $005 / 66$ \\
& & $21 / 08 / 2007$ & $005 / 65$ \\
2008 & TM & $06 / 07 / 2008$ & $005 / 66$ \\
& & $06 / 07 / 2008$ & $005 / 65$ \\
2010 & TM & $28 / 07 / 2010$ & $005 / 66$ \\
\hline
\end{tabular}

Utilizaram-se, em relação ao relevo, informações a partir de radar obtidas de sensores a bordo do ônibus espacial Endeavour, no projeto SRTM (Shuttle Radar Topography Mission) (Figura 2).

Para o processamento das imagens empregou-se o algoritmo SEBAL (Surface Energy Balance Algoritm for Land) proposto por (Bastiaanssen et al., 1998), com auxílio do software ERDAS IMAGINE 10. Nesse processo foi adotada uma série de sequências e processamentos (Figura 3) com base nas metodologias: Chander \& Markhan (2003), Allen et al. (2007) e Rouse et al. (1973) no ERDAS IMAGINE 10.

O software ArcGIS 9.3 foi utilizado para o trabalho de dados vetoriais das bacias hidrográficas, como: cálculo de área, perímetro, comprimento natural e axial dos igarapés, além do banco de dados e mapas.

Na classificação não supervisionada adotou-se a metodologia proposta por Freitas et al. (2012) visando mapear as áreas

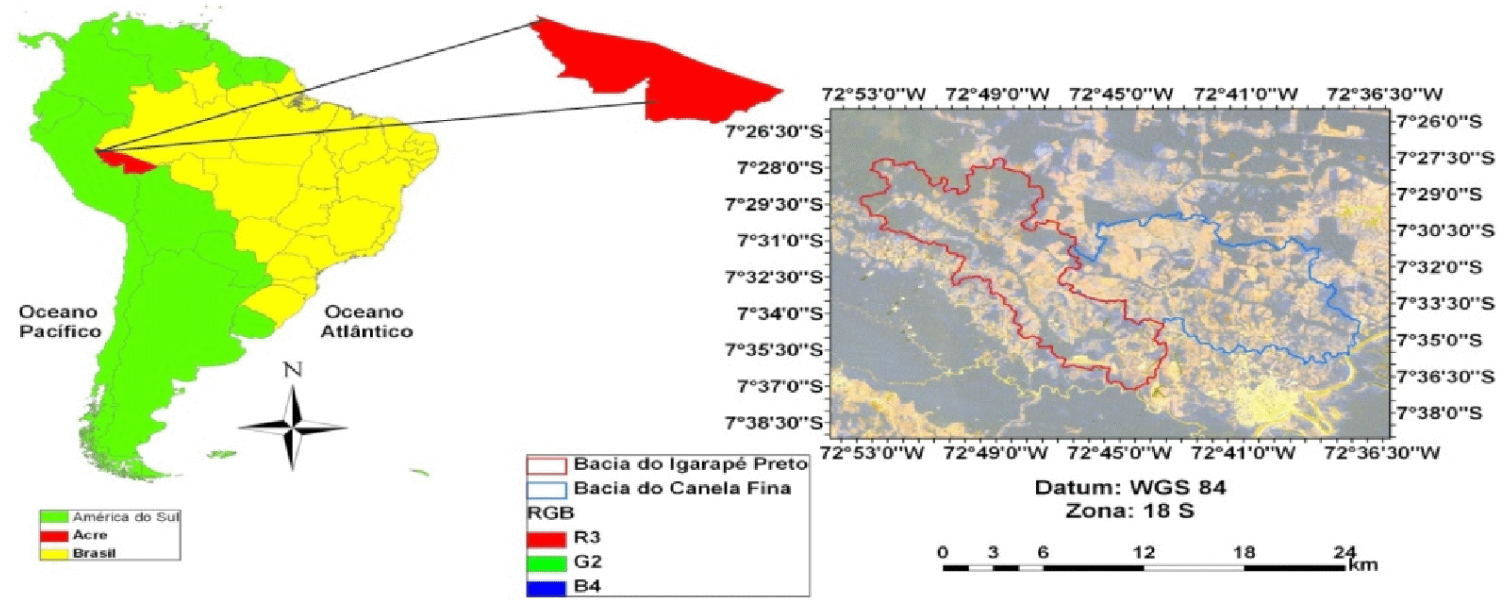

Figura 1. Localização geográfica da área de estudo e no segundo plano a localização da Bacia Hidrográfica do Igarapé Preto (BHIP) e do Igarapé Canela Fina (BHICF) com a composição RGB (3, 2 e 4), para o dia 14/07/2005 


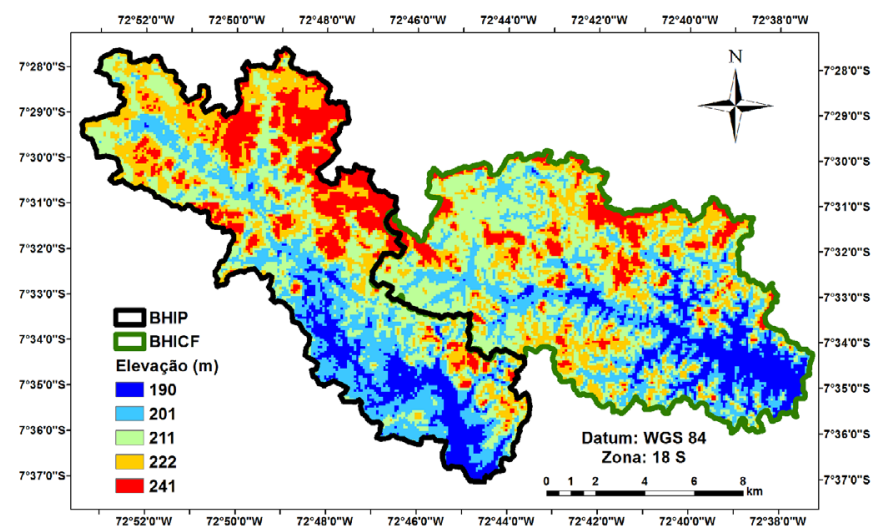

Figura 2. Modelo Digital de Elevação (MDE) para a Bacia Hidrográfica do Igarapé Preto (BHIP) e do Igarapé Canela Fina (BHICF), município de Cruzeiro do Sul/Acre

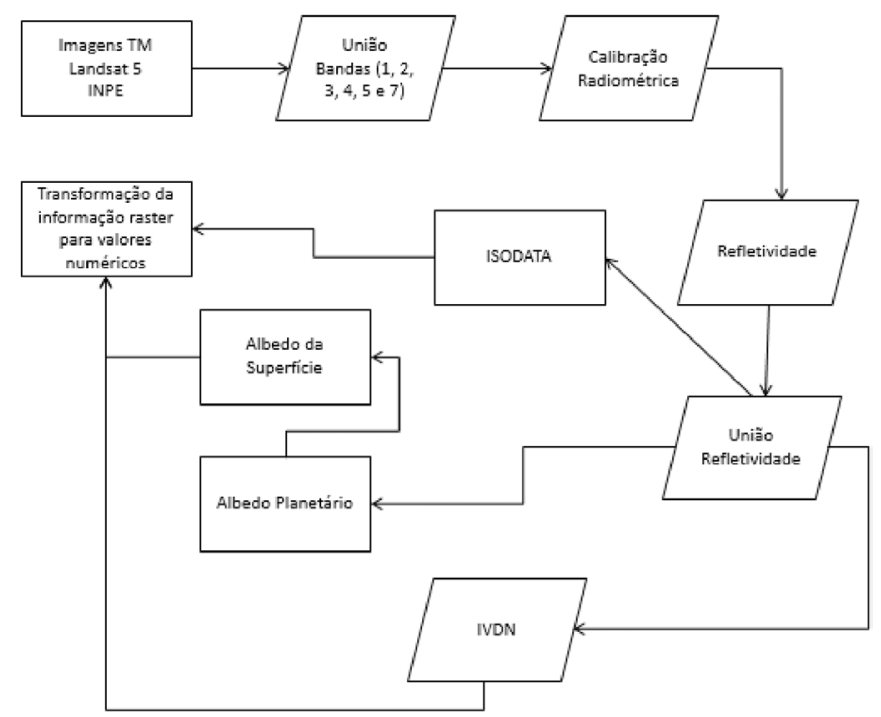

Figura 3. Fluxograma do sistema de processamento das imagens do sensor TM e a classificação não supervisionada pelo método ISODATA para a Bacia Hidrográfica do Igarapé Preto (BHIP) e do Igarapé Canela Fina (BHICF), município de Cruzeiro do Sul, Acre

de floresta, desflorestamento e água para as duas bacias hidrográficas, conforme descrito na (Figura 3).

Para cada bacia hidrográfica foram calculados, na sequência, a área total de cada bacia hidrográfica $\left(\mathrm{km}^{2}\right)$ e o perímetro $(\mathrm{km})$ e, aplicando-se as Eqs. 1, 2, 3 e 4 descritas por Cardoso et al. (2006), o coeficiente de compacidade (Kc), o fator de forma (F), índice de circularidade (IC) e a densidade de drenagem (Dd) respectivamente.

$$
\mathrm{Kc}=0,28 \times \frac{\mathrm{P}}{\sqrt{\mathrm{A}}}
$$

em que:

Kc - coeficiente de compacidade

$\mathrm{P}$ - perímetro da bacia hidrográfica, $\mathrm{m}$

A - área de drenagem da bacia hidrográfica, $\mathrm{m}^{2}$

$$
\mathrm{F}=\frac{\mathrm{A}}{\mathrm{L}^{2}}
$$

em que:

$\mathrm{F}$ - fator de forma

A - área de drenagem da bacia hidrográfica, $\mathrm{m}^{2}$

L - comprimento do eixo da bacia hidrográfica, m

$$
\mathrm{IC}=\frac{12,57 \times \mathrm{A}}{\mathrm{P}^{2}}
$$

em que:

IC - índice de circularidade

A - área de drenagem da bacia hidrográfica, $\mathrm{m}^{2}$

P - perímetro da bacia hidrográfica, $m$

$$
\mathrm{Dd}=\frac{\mathrm{L}_{\mathrm{t}}}{\mathrm{A}}
$$

em que:

Dd - densidade de drenagem, $\mathrm{km} \mathrm{km}^{-1}$

Lt - comprimento total de todos os canais, $\mathrm{km}$

A - área de drenagem da bacia hidrográfica, $\mathrm{km}^{2}$

\section{Resultados e Discussão}

A identificação das razões de áreas de desflorestamento nas bacias hidrográficas em estudo se deu através de uma classificação não supervisionada. Verificou-se, através da classificação espectral pelo método ISODATA, que as áreas desflorestadas estão sendo substituídas por culturas agrícolas da região, áreas de pastagem e urbanização, sendo que tais categorias foram classificadas apenas como área desflorestada.

Observa-se diminuição do índice de vegetação da diferença normalizada (IVDN) nos anos de 2005 a 2010; esta alteração proporciona diversos problemas no ecossistema; com a ausência de cobertura florestal ocorrerá, consequentemente, uma diminuição das populações faunísticas que se beneficiam dos recursos provenientes da floresta, como também da possível extinção de espécies vegetais.

Para os anos de 2006 e 2008 o IVDN apresentou valores médios altos 0,66 respectivamente. Utilizaram-se datas diferentes para compor o mosaico das bacias hidrográficas (02/08/2006 e 14/05/2006), valores mais altos foram influenciados para a cena do dia 02/08/2006 e os mais baixos foram encontrados na transição do período chuvoso para o seco, dia 14/05/2006.

No ano de 2007 se encontra um valor significativamente baixo 0,52 tendo, porém, um acréscimo deste valor no ano seguinte, 2008, com 0,66 (Figura 4).

Para o ano de 2010 o IVDN apresenta valores menores que o ano de 2008, com 0,59. Tais alterações do IVDN durante o período de estudo podem estar associadas a fatores morfológicos, stress hídrico, precipitação e radiação solar. Sendo que a precipitação (Delgado et al., 2012a) e a radiação solar são fundamentais para o crescimento e regeneração natural da vegetação. 


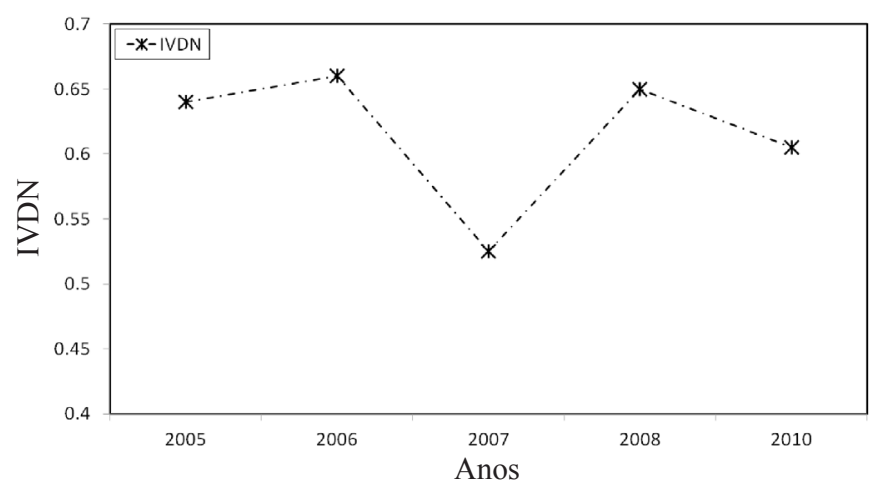

Figura 4. Valores médios do índice de vegetação da diferença normalizada (IVDN), para Bacia Hidrográfica do Igarapé Preto (BHIP) e do Igarapé Canela Fina (BHICF)

O ano de 2005 apresentou valores significativamente baixos deste índice. De acordo com CPTEC/INMET (2005) eventos de estiagem nessas regiões são raros cujos registros indicam que o ano de 2005 teve o menor índice pluviométrico das últimas décadas.

Os valores encontrados de IVDN das BHIP e BHICF para o período em estudo apresentam tendência decrescente, ou seja, o índice de vegetação caminha no decorrer dos anos para um declínio de seus valores (Figura 4).

Freitas et al. (2012) também encontraram, estudando a variabilidade espacial e temporal de imagens TM no município de Acrelândia, estado do Acre, redução significativa em 12 anos de imagens do Índice de Vegetação da Diferença Normalizada (IVDN). Mencionados autores identificaram, através da classificação por ISODATA, a substituição de áreas de florestas para pastagem e agricultura.

Analisando a Figura 5 observa-se uma diminuição nas áreas de floresta ao longo dos anos de 2005, 2006, 2007, 2008 e 2010 , correspondendo a, respectivamente, 57,$88 ; 59,77 ; 48,20$; 45,00 e $42,24 \%$.

Para o ano de 2005, período extremamente seco em todo o estado do Acre (CPTEC/INMET, 2005) observa-se um valor mínimo de floresta comparando-o a 2006; é provável

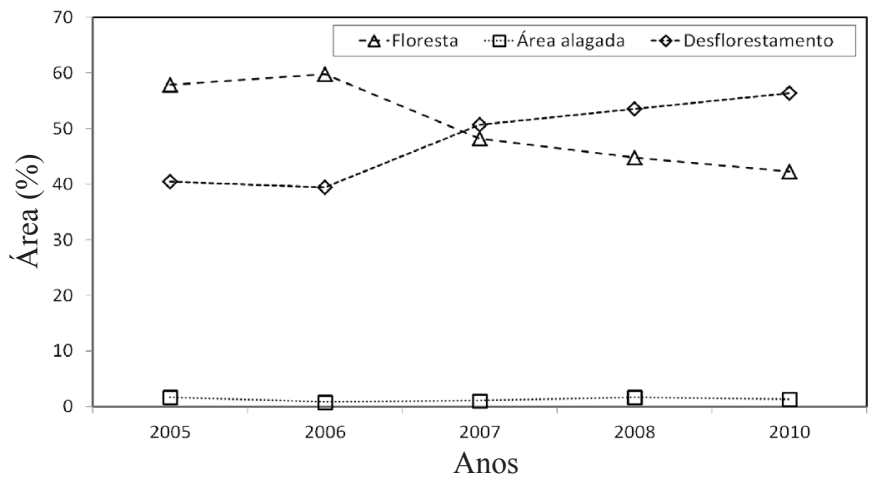

Figura 5. Áreas de floresta, desflorestamento e lâmina de água entre os anos de 2005 a 2010 para a Bacia Hidrográfica do Igarapé Preto (BHIP) e do Igarapé Canela Fina (BHICF) no município de Cruzeiro do Sul, Acre que este aumento tenha sido consequência da regeneração da floresta após o período de seca; para os demais anos, 2007 a 2010, a tendência de decréscimo do ativo florestal de $54 \%$ é relativamente alta (Figura 5).

Em estudo recente através da classificação espectral de imagens TM, para os municípios de Cruzeiro do Sul e Acrelândia, estado do Acre, os autores Delgado et al. (2012a) e Freitas et al. (2012) constataram aumento das áreas de pastagem indicando que algumas dessas passaram por processos de regeneração de floresta.

Para os anos de 2005 a 2010 (Figura 5) ocorreu um aumento acelerado das áreas desmatadas de 40,49; 39,40; 50,75; 53,51 e 56,42\%, explicado pelas grandes áreas antropizadas, principalmente o aumento das áreas de pastagem e cultivos agrícolas na região.

Os valores percentuais de áreas alagadas para os anos de 2005, 2006, 2007, 2008 e 2010 foram de 1,63; 0,83; 1,05; 1,66 e $1,34 \%$, respectivamente (Figura 5). Há uma oscilação das áreas alagadas passível de poder ser atribuída a modificações na superfície do solo destinadas à construção de obras hidráulicas, como açudes e barragens, nos últimos anos.

Segundo Matos et al. (2003) mesmo que barragens sejam projetadas dentro das técnicas modernas de construção, provocam impactos ambientais negativos e por esta razão na concepção, dimensionamento, implantação e operação de barragens, o empreendedor deve, então, adotar uma série de medidas para atenuar esses impactos ambientais negativos.

A construção do reservatório de Sobradinho, no rio São Francisco, associada às demais atividades desenvolvidas na bacia, causou redução da vazão média da ordem de $163 \mathrm{~m}^{3} \mathrm{~s}^{-1}$ (Pereira et al., 2009).

Tucci \& Clarke (1997) destacam que as modificações, sejam elas naturais e/ou artificiais, na cobertura vegetal das bacias hidrográficas, influenciam o comportamento hidrológico; essas alterações produzem diversos impactos sobre o meio ambiente e na sua disponibilidade hídrica.

Ao estudar a influência da mudança da paisagem no município de Cruzeiro do Sul/AC, Delgado et al. (2012b) constataram o crescimento médio de mais de 54 mil hectares das áreas antropizadas durante os anos de 2005 a 2010.

Analisando os valores de albedo (Figura 6) concluiu-se que o ano de 2005 apresentou menor valor sendo este correspondente a 11\%; em contrapartida, o ano de 2010 apresentou o maior, com $17 \%$;

Cunha et al. (2012) encontraram, ao estudar a dinâmica da cobertura vegetal para a Bacia de São João do Rio do Peixe, PB, valores menores para os corpos d' água ( 0 e 0,03$)$, intermediários para as áreas vegetadas $(0,12$ e 0,21$)$ e valores acima de 0,24 referindo-se às áreas com pouca cobertura vegetal ou solo exposto.

As características físicas calculadas para ambas as bacias hidrográficas são apresentadas na (Tabela 2). Com base nos índices calculados constatou-se uma similaridade geométrica entre ambas. De acordo com Goldenfum (2001) a identificação de áreas com comportamento similar possibilita a transferência de informações hidrológicas de um local para outro. 


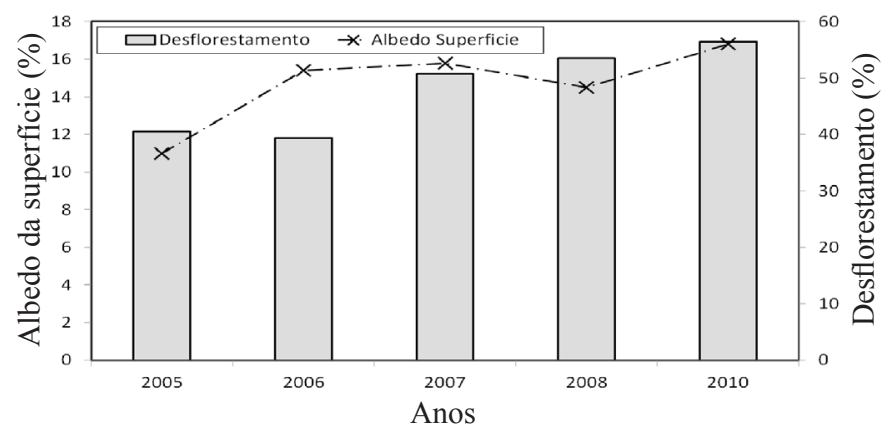

Figura 6. Valores médios de albedo da superfície e desflorestamento para a Bacia Hidrográfica do Igarapé Preto (BHIP) e do Igarapé Canela Fina (BHICF) na região de Cruzeiro do Sul/Acre

Tabela 2. Características físicas das Bacias Hidrográficas do Igarapé Preto (BHIP) e do Igarapé Canela Fina (BHICF), no município de Cruzeiro do Sul/Acre

\begin{tabular}{lrr}
\hline \multicolumn{1}{c}{ Características físicas } & BHICF & BHIP \\
Área $\left(\mathrm{km}^{2}\right)$ & 116,79 & 116,85 \\
Perímetro $(\mathrm{km})$ & 70,22 & 87,32 \\
Largura média $(\mathrm{km})$ & 6,40 & 5,32 \\
Densidade de drenagem $\left(\mathrm{D}_{\mathrm{d}}\right)\left(\mathrm{km} \mathrm{km}^{-2}\right)$ & 0,83 & 0,86 \\
Coeficiente de compacidade $(\mathrm{Kc})$ & 1,82 & 2,26 \\
Fator de forma $(\mathrm{F})$ & 0,40 & 0,24 \\
Índice de circularidade $(\mathrm{IC})$ & 0,30 & 0,19 \\
Rede de drenagem $(\mathrm{km})$ & 97,16 & 100,51 \\
Comprimento do igarapé principal $(\mathrm{km})$ & 19,35 & 26,93 \\
Comprimento axial $(\mathrm{km})$ & 17,08 & 22,24 \\
Altitude maior $(\mathrm{m})$ & 241 & 238 \\
Altitude menor $(\mathrm{m})$ & 171 & 170 \\
Altitude média $(\mathrm{m})$ & 206 & 204 \\
Número de drenos & 39 & 30 \\
\hline
\end{tabular}

Em relação à área total das bacias hidrográficas, a diferença entre elas é de 6 ha, segundo Silveira (2001) a área da bacia hidrográfica é um dado fundamental para definir sua potencialidade hídrica, haja vista que seu valor define, multiplicado pela lâmina da chuva precipitada, o volume de água recebido pela bacia.

A altitude média das bacias hidrográficas é de aproximadamente $205 \mathrm{~m}$, na BHICF a altitude máxima é superior a BHIP (241 e $238 \mathrm{~m}$ ) respectivamente.

A diferença de nível entre os pontos é de 70 e $68 \mathrm{~m}$ para BHICF e BHIP. As águas da BHICF deságuam abaixo da cidade de Cruzeiro do Sul no Rio Juruá enquanto a BHIP desagua acima da cidade, no Rio Moa.

A declividade média dos cursos de água principal foi de $0,0036 \mathrm{~m} \mathrm{~m}^{-1}$ para a BHICF e $0,0025 \mathrm{~m} \mathrm{~m}^{-1}$ para a BHIP. A declividade média do curso d'água principal é outro aspecto relevante da morfometria uma vez que interfere na velocidade do escoamento da água no curso (Tonello et al., 2006).

Com base nos valores calculados pode-se dizer que os cursos de água principal das bacias hidrográficas possuem baixa declividade. A brusca suavização e o aplainamento do terreno são indicativos de escoamento lento, a magnitude dos picos de enchentes ou menor oportunidade de infiltração e suscetibilidade à erosão dos solos dependem da rapidez com que ocorre o escoamento superficial (Coutinho et al., 2011).
Os índices calculados de Kc, Kf e IC indicam que as bacias hidrográficas possuem formato alongado, isto é, quanto mais esses índices se afastam da unidade menor a chance da bacia hidrográfica possuir formato circular e, portanto, menor risco de enchentes.

Resultados semelhantes foram obtidos na microbacia do córrego Ipaneminha na região de Sorocaba/SP e na bacia hidrográfica do rio Debossan em Nova Friburgo/RJ (Pinheiro et al., 2011; Cardoso et al., 2006); os autores destacam que quanto mais esses índices se distanciam da unidade e quanto mais próximos de zero for o Kf, menor será a susceptibilidade a enchentes.

Tonello et al. (2006) destacam, estudando a bacia hidrográfica da cachoeira das Pombas na região de Guanhães/MG que também apresenta formato alongado, que o menor risco de enchentes nesse tipo de bacia é atribuído às condições normais de precipitação.

Teodoro et al. (2007) estudando as características morfométricas da microbacia do córrego Marivan inserida na região de Araraquara, estado de São Paulo, verificaram que os índices Kf e IC indicaram que o perímetro da bacia se aproxima a uma forma círcular, o que favorece os processos de inundação (cheias rápidas).

Silva (2003) também verificou que a bacia do córrego Capetinga, localizada na região sudoeste do Distrito Federal, possui formato bastante arredondado e, consequentemente, propicia cheias elevadas e de curta duração; o Kc calculado foi de 1,09 e a Dd de $0,49 \mathrm{~km} \mathrm{~km}^{-1}$.

Para a BHICF e BHIP, os valores de Dd são considerados baixos; segundo Villela \& Mattos (1997) este índice pode variar de 0,5 a $3,5 \mathrm{~km} \mathrm{~km}^{-2}$ em bacias com drenagem pobre e bacias excepcionalmente bem drenadas, em que se pode inferir que as duas bacias hidrográficas, objeto de estudo, possuem drenagem deficitária além de responderem lentamente a eventos hidrológicos.

Valores reduzidos de Dd geralmente estão associados a regiões de rochas permeáveis e de regime pluviométrico caracterizado por chuvas de baixa intensidade ou pouca concentração da precipitação (Tonello et al., 2006).

\section{Conclusões}

1. Os resultados obtidos apontam que as alterações ambientais ocorridas ao longo dos últimos anos nas bacias hidrográficas possivelmente influenciaram na dinâmica dos igarapés.

2. O sensoriamento remoto como ferramenta de análise espaço-temporal de classes de floresta, desflorestamento e áreas alagadas mostrou-se eficaz quanto à utilização em bacias hidrográficas.

\section{Agradecimentos}

À Universidade Federal do Acre, pela concessão de Bolsa de Iniciação Científica, Pibic/UFAC no período de 2009/2010 e 2010/2011 ao primeiro autor, ao CNPq pelo auxílio financeiro 
processo 477207/2011-1 e à Universidade Federal Rural do Rio de Janeiro, pela disponibilidade do uso do laboratório para as atividades de pesquisas.

\section{Literatura Citada}

Allen, R.; Tasumi, M.; Trezza, R. Satellite-based energy balance for mapping evapotranspiration with internalized calibration (METRIC) - Model. Journal of Irrigation and Drainage Engineering, Reston, v.133, p.380-394, 2007.

Bastiaanssen, W. G. M.; Menenti, M.; Feddes, R. A. A. M. A remote sensing surfasse energy balance algorithm for land (SEBAL) 1. Formulation. Journal of Hydrology. v.212-213, p.198-212, 1998.

Bezerra, M. V. C.; Silva, B. B.; Bezerra, B. G. Avaliação dos efeitos atmosféricos no albedo e NDVI obtidos com imagens de satélite. Revista Brasileira de Engenharia Agrícola e Ambiental, v.15, p.709-717, 2011.

Cardoso, C. A.; Dias, H. C. T.; Soares, C. P. B.; Martins, S. V. Caracterização morfométrica da bacia hidrográfica do Rio Debossan, Nova Friburgo, RJ. Revista Árvore, v.30, p.241248, 2006.

Chander, G.; Markham, B. Revised Landsat 5/TM radiometric calibration procedures and postcalibration dynamic ranges. IEEE Transactions on Geosciense and Remote Sensing, v.41, p.2.764-2.677, 2003.

Coutinho, L. M.; Cecílio, R. A.; Xavier, A. L.; Zanetti, S. S.; Garcia, G. O. G. Caracterização morfométrica da bacia hidrográfica do rio da Prata, Castelo, ES. Irriga, v.16, p.369381, 2011.

CPTEC/INMET. Seca da Amazônia em 2005. Nota ao público em geral elaborada pelo Centro de Previsão de Tempo e Estudos Climáticos (CPTEC) em conjunto com o Instituto Nacional de Meteorologia (INMET). Brasília: Agência CT, Ministério da Ciência e Tecnologia, 2005. 3p.

Cunha, J. E. B. L.; Rufino, L. A. A.; Silva, B. B.; Chaves, I. B. Dinâmica da cobertura vegetal para a Bacia de São João do Rio do Peixe, PB, utilizando-se sensoriamento remoto. Revista Brasileira de Engenharia Agrícola e Ambiental, v.16, p.539-548, 2012.

Delgado, R. C.; Sediyama, G. C.; Costa, M. H.; Soares, V. P.; Andrade, R. G. Classificação espectral de área plantada com a cultura da cana-de-açúcar por meio da árvore de decisão. Revista Engenharia Agrícola, v.32, p.369-380, 2012 b.

Delgado, R. C.; Souza, L. P.; Silva, I. W. R.; Pessôa, C. S.; Gomes, F. A. Influência da mudança da paisagem amazônica no aumento da precipitação em Cruzeiro do Sul, AC. Enciclopédia Biosfera, v.8, p.665-674, 2012a.
Feldmann, F. Guia da ecologia: Para entender e viver melhor a relação homem natureza. São Paulo: Abril, 1992. 320p.

Freitas, D. M.; Delgado, R. C.; Rodrigues, R. A.; Souza, L. P. Variabilidade espaço-temporal na mudança da paisagem no município de Acrelândia, AC. Enciclopédia Biosfera, v.8, p.935-946, 2012.

Goldenfum, J. A. Pequenas bacias hidrográficas: conceitos básicos. In: Tucci, C. E. M. (Organizador). Hidrologia: ciência e aplicação. 2.ed. Porto Alegre. UFRGS: ABRH, 2001. Cap.1, p.3-13.

Matos, A. T.; Silva, D. D.; Pruski, F. F. Impactos decorrentes da construção de reservatórios para acumulação de água. ITEM: Irrigação e tecnologia moderna. Brasília, n. 56/57, p.60-66, 2003.

Pereira, S. B.; Pruski, F. F.; Silva, D. D.; Ramos, M. M. Evaporação líquida no lago de Sobradinho e impactos devido à construção do reservatório. Revista Brasileira de Engenharia Agrícola e Ambiental, v.13, p.346-352, 2009.

Pinheiro, R. C.; Tonello, K. C.; Valente, R. O. A.; Mingoti, R.; Santos, I. P. Ocupação e caracterização hidrológica da microbacia do córrego Ipaneminha, Sorocaba- SP. Irriga, v.16, p.234-245, 2011.

Rouse, J. W.; Haas, R. H.; Schell, J. A.; Deering, D. W. Monitoring vegetation systems in the great plains with ERTS. In: Earth Resources Technology Satellite-1 Symposium, 3, 1973, Washington. Proceedings... Washington: NASA, 1973. v.1, p.309-317.

Silva, C. L. Análise estatística das características da vazão do córrego Capetinga. Revista Brasileira de Engenharia Agrícola e Ambiental, v.7, p.311-317, 2003.

Silveira, A. L. L. Ciclo hidrológico e bacia hidrográfica. In: Tucci, C. E. M. (org.). Hidrologia: ciência e aplicação. 2. ed. Porto Alegre. UFRGS: ABRH, 2001. Cap.2, p.35-51.

Teodoro, V. L. I.; Teixeira, D.; Costa, D. J. L.; Fuller, B. B. 2007. O conceito de bacia hidrográfica e a importância da caracterização morfométrica para o entendimento da dinâmica ambiental local. Revista Uniara, v.20, p.137-156, 2007.

Tonello, K. C.; Dias, H. C. T.; Souza, A. L.; Ribeiro, C. A. A. S.; Leite, F. P. Morfometria da bacia hidrográfica da cachoeira das pombas, Guanhães - MG. Revista Árvore, v.30, p.849857, 2006.

Tucci, C. E. M.; Clarke, R. T. Impacto das mudanças da cobertura vegetal no escoamento: Revisão. Revista Brasileira de Recursos Hídricos, v.2, p.135-152, 1997.

Villela, S. M.; Mattos, A. Hidrologia aplicada. São Paulo: McGraw-Hill do Brasil, 1997. 245p. 